\title{
Preparation and Characterization of
}

\section{Tacrolimus-Loaded SLNs in situ Gel for Ocular Drug Delivery for the Treatment of Immune Conjunctivitis}

\author{
This article was published in the following Dove Press journal:
}

Drug Design, Development and Therapy

\section{Kexin Sun \\ $\mathrm{Ke} \mathrm{Hu}$}

Department of Ophthalmology, The First Affiliated Hospital of Chongqing Medical University, Chongqing Key Laboratory of Ophthalmology, Chongqing Eye Institute, Chongqing, People's Republic of China
Correspondence: Ke Hu Email kehu20202020@I63.com

Kexin Sun

Email skxsunny@stu.cqmu.edu.cn
Background: The aim of this study is to develop a novel in situ gel of tacrolimus-loaded SLNs (solid lipid nanoparticles) for ocular drug delivery.

Methods: The optimal formulation was characterized by surface morphology, particle size, zeta potential, entrapment efficiency, drug loading and in vitro release behavior. In vivo studies were also conducted to evaluate the pharmacokinetic and pharmacodynamic results.

Results: In this study, TAC-SLNs ISG were prepared using homogenization followed by probe sonication method. The average particle size of TAC-SLNs ISG was observed to be $122.3 \pm 4.3$ $\mathrm{nm}$. Compared with TAC-SLNs, in situ gel did not increase particle size, and there was no significant difference between them. The results of viscosity measurement showed that TAC SLNs-ISG were typical of pseudo plastic systems and showed a marked increase in viscosity as temperature increased and ultimately formed a rigid gel $\left(32^{\circ} \mathrm{C}\right)$. In vitro and in vivo studies illustrated the sustained release model of the drug from TAC-SLNs ISG. Animal model showed that TAC-SLNs ISG had good pharmacodynamics when compared with eye drops and SLNs. Conclusion: Our results demonstrated that TAC SLNs-ISG had the potential for being an ideal ocular drug delivery system.

Keywords: tacrolimus, in situ gel, SLNs, ocular drug delivery

\section{Introduction}

Immune mediated inflammatory anterior segment diseases (IIAODs) are a kind of common ophthalmic diseases, including conjunctivitis and anterior uveitis. This kind of disease may cause some serious complications and sequelae, which is one of the main causes of blindness. Conjunctivitis requires antibiotic treatment for 5-7 days, which may lead to poor compliance with conventional dosage forms because of the higher frequency of administration, ie 2 drops per day. The reason for that is in the process of ophthalmic administration, due to the physiological constraints of eye protection mechanism, the drug absorption rate is low and the duration of treatment effect is short. When the drug solution drops into the eye, effective tear drainage and blinking can reduce the drug concentration by 10 times in 4-20 minutes. ${ }^{1}$ We can improve the ocular therapy by improving the precorneal residence time of drugs. In order to slow down drug elimination and to prolong the resident time on the ocular surface, several new preparations have been developed for ocular use, such as liposomes, nanoparticles and nanocapsules. ${ }^{2-8}$

Many agents available for the treatment of conjunctivitis and tacrolimus (TAC) are the widely used novel macrolide immunosuppressants. However, TAC is 
a highly lipophilic macrolide lactone and therefore shows very poor water-solubility of $1-2 \mu \mathrm{g} / \mathrm{mL} .^{9-13}$ Marketed as eye drops, rapid precorneal drainage requires frequent instillation or use of high drug concentration which usually leads to a pulse kinetics pattern of drug concentration. At the same time, another problem is easy hydrolysis, resulting in very low stability in aqueous solutions. ${ }^{14}$ Therefore, TAC was prepared as an eye drop dispersion containing nearly $100 \%$ undissolved TAC. However, drugs, such as TAC, should usually be dissolved to facilitate effective transport or penetration and reach the target site for therapeutic effect. ${ }^{15}$ It is expected that dissolved TAC will penetrate into the eye tissue more quickly, thus improving bioavailability and reducing treatment failure. ${ }^{15}$

It can be seen that researchers need to develop a new drug delivery system to meet the better clinical effect, whether from the perspective of human physiology or of the physical and chemical properties of the drug itself. In situ gel is a hot spot in the research of ocular drug delivery system in recent years. It exhibits reversible phase transitions (sol-gel-sol) and pseudoplastic behavior to minimize drainage from blinking. ${ }^{16}$ In situ gel is formulated as a liquid dosage form which is suitable to be administered as conventional eye drops which, upon exposure to eye physiological conditions, change to the gel phase, thus increasing the precorneal residence time of the delivery system and enhancing ocular bioavailability.

Meanwhile solid lipid nanoparticles (SLNs) have been used for ocular drug delivery amongst different lipid nano carriers. The biggest advantage of SLNs is that it has the capability to encapsulate lipophilic molecules inside the lipid matrix and improve the poor solubility or permeability of the drug. ${ }^{17,18}$ Previously, SLNs have been used as an ocular delivery platform for the delivery of various drugs, including natamycin, ${ }^{19}$ triamcinolone, ${ }^{20}$ indomethacin, ${ }^{21}$ atorvastatin, ${ }^{22}$ a platform that is more beneficial than other conventional preparation systems (solutions and suspensions). However, TAC loaded SLNs in situ gel (TACSLNs-ISG) is still an unexplored area in the field of intraocular transport.

The objective of the present study is to develop an ocular system combining SLNs and in situ gel for TAC, and to compare the system with plain eye drops and SLNs formulations. The optimal formulation was characterized by surface morphology, particle size, zeta potential, entrapment efficiency, drug loading and in vitro release behavior. In vivo studies were also conducted to evaluate the pharmacodynamic results.

\section{Materials and Methods}

\section{Materials}

TAC was purchased from Kerui Pharmaceutical Co., Ltd (Fujian, China). Compritol ${ }^{\circledR} 888$ ATO (glyceryl behenate) and glyceryl monostearate (GMS) were purchased from Gattefossé. Pluronic ${ }^{\circledR}$ F-68 (Poloxamer 188), Pluronic ${ }^{\circledR}$ F-127 (Poloxamer 407) and Tween ${ }^{\circledR} 80$ were obtained from Sinopharm Chemical Reagent (Shanghai, China). All the other reagents used were of analytical grade and were used without further purification.

\section{Preparation of TAC SLNs-ISG}

TAC SLNs-ISG were prepared by using homogenization coupled with ultra-probe sonication method. ${ }^{23}$ Briefly, Compritol $^{\circledR} 888$ ATO $(0.25 \%, w / v)$ and GMS $(2 \%, w / v)$ were dissolved in the dichloromethane $(2 \mathrm{~mL})$ and were heated to $80{ }^{\circ} \mathrm{C}$, after that TAC $(0.1 \%$, w/v $)$ was added under magnetic stirring until a clear drug-lipid phase was obtained. The organic solvent was evaporated in vacuum at $45^{\circ} \mathrm{C}$ to form the lipid film, which was further dried in the vacuum drying oven at $37^{\circ} \mathrm{C}$ to remove the residual organic solvent. Simultaneously, the aqueous phase, consisting of Tween-80 $(0.5 \%, \mathrm{w} / \mathrm{v})$ and glycerin $(2 \%, \mathrm{w} / \mathrm{v})$ in distilled water, was heated $\left(30^{\circ} \mathrm{C}\right)$ and transferred to the molten drug-lipid mixture under constant stirring, to form a pre-mixture. The mixture was homogenized with a probe-type ultrasonicator (S220, Covaris, USA) in the ice bath for 10 cycles to get the TAC SLNs. Then TAC SLNs-ISG was obtained by mixing TAC SLNs and Poloxamer 188 (12\%, w/v)/Poloxamer 407 (26\%, w/v) solution in the ice bath.

\section{Characterization of System}

\section{Particle Size and Zeta Potential}

Intensity-mean particle size, zeta potential and polydispersity index of TAC SLNs-ISG were determined using a Zetasizer NanoZS (Malvern Instruments Ltd.). All measurements were performed under automatic mode at $25^{\circ} \mathrm{C}$. The hydrodynamic diameter was calculated from autocorrelation function of the intensity of light scattered from particles with the assumption that the particles have a spherical form.

\section{Entrapment Efficiency}

The entrapment efficiency ( $\%$ EE) was determined by measuring the concentration of unentrapped drug in the lipid dispersion. Briefly, the SLNs-ISG dispersion was subjected to 
centrifugation for $30 \mathrm{~min}, 4^{\circ} \mathrm{C}$ at $6000 \mathrm{rpm}$ and the amount of TAC in supernatant was determined by dissolving supernatant in acetone and $0.1 \%$ acetic acid (1:1) mixture by HPLC. The amount of free drug in the supernatant was determined spectrophotometrically at $210 \mathrm{~nm}$. The entrapment efficiency was determined in triplicate and calculated as follows.

$\mathrm{EE} \%=\mathrm{W}_{\mathrm{TAC}} /\left(\mathrm{W}_{\mathrm{SLNs}-\mathrm{ISG}}+\mathrm{W}_{\mathrm{TAC}}\right) \times 100 \%$

$\mathrm{W}_{\mathrm{TAC}}$ represents the amount of TAC loaded in the SLNs-ISG,

$\mathrm{W}_{\text {SLNs-ISG }}$ represents the weight of the TAC SLNs-ISG.

\section{Viscosity Experiments}

The sol-gel transition temperature of TAC SLNs-ISG sol in water was measured by the tube transformation method. ${ }^{24}$ A vial containing $20 \mathrm{~mL}$ TAC SLNs-ISG sol was immersed in an oil bath at different temperatures to achieve equilibrium. When the flow rate was no longer visually observable within $30 \mathrm{~s}$ by inverting the vial, the temperature was increased by $2^{\circ} \mathrm{C}$ per step, and the sample was regarded as a "gel". The viscosity of TAC SLNsISG in solution or gel was then measured using a rotating viscometer (60 rpm, rotor 2) with suitable samples $(20 \mathrm{~mL})$. The appropriate number of spindles was used for measurement at different speeds. The viscosity was read directly from the viscometer display.

\section{In vitro Release}

The in vitro release studies were conducted by a dynamic dialysis method. Briefly, TAC SLNs-ISG containing $20 \mathrm{mg}$ were placed into dialysis bags, which were then placed into an end-sealed vial. The release medium was $2000 \mathrm{~mL}$ simulated tear fluid (STF; made with sodium chloride- $0.67 \mathrm{~g}$, sodium bicarbonate- $0.20 \mathrm{~g}$, calcium chloride dihydrate $-0.008 \mathrm{~g}$ in distilled water q.s $100 \mathrm{~mL}$ ). The sealed vials were maintained at $37^{\circ} \mathrm{C}$ and $75 \mathrm{rpm}$ in a gas bath thermostatic oscillator. Aliquots $(1 \mathrm{~mL})$ were withdrawn at intervals of $0.25,0.5,1$, $2,4,6,8,12$, and $16 \mathrm{~h}$, and the same replacement volume was supplied as the release medium. The collected samples were determined by HPLC. An equal amount of free TAC and TAC SLNs was used for comparison.

\section{Stability Studies}

Stability studies were carried out on TAC SLNs-ISG according to $\mathrm{ICH}$ (International Conference on Harmonization) Guidelines at $40^{\circ} \mathrm{C}, 75 \%$ relative humidity. Three packs of formulations were subjected to these stability studies. The samples were withdrawn at the 0th, 1st and 3rd month. Every time $0.1 \mathrm{~mL}$ of samples were withdrawn and analyzed for the assay with HPLC for the drug content. At the same time, some other stability parameters were also determined.

\section{In vivo Kinetics}

In vivo ocular disposition studies of TAC SLNs-ISG and TAC SLNs in comparison with TAC eye drops, were carried out in New Zealand rabbits, weighing between 2 to $3 \mathrm{~kg}$. The rabbits were allowed to acclimatize to the new surroundings for one week, and the ocular disposition studies were then performed. A formulation of $50 \mu \mathrm{L}$ of the TAC SLNs-ISG, TAC SLNs and TAC eye drop $(0.1 \% \mathrm{w} / \mathrm{v})$ was dripped into the cul-de-sac of the right eye while the left eye served as the control. Approximately five microliters of tear were collected from the cul-de-sac of the test eye, using a micropipette, at 15th, 30th min, 1st, 2nd, 4th, 5th, 6th, 8th and 10th $\mathrm{h}$. Ten hours later, the rabbits were euthanized by intravenous injection of pentobarbital. Rinse eyes with cold DPBS and remove them immediately. The eye tissues were carefully separated and stored at $-80^{\circ} \mathrm{C}$ until further analysis. Tear samples were collected in acetone: $0.1 \%$ acetic acid $=(1: 1)$ and analyzed by HPLC. The ocular tissue samples were extracted using acetone precipitation method and analyzed using LC-MS/MS system. Separation was achieved on a Genesis C18 column with a gradient mobile phase elution. Ammonium-adduct ions formed by a Turbo Ionspray in positive ion mode were used to detect each analyte. The MS/MS detection was traced by monitoring the fragmentation of $807.5 \rightarrow 772.4(\mathrm{~m} / \mathrm{z})$ for TAC on a triple quadrupole mass spectrometer (Sciex API 3000). The above method was simple, fast, and specific. The calibration curve of the LC assay for TAC in neat solution has good linearity $\left(r^{2}=0.996\right)$ over the range of $10-10,000 \mathrm{ng} /$ $\mathrm{mL}$. The lower limit of the quantitation of TAC in the LC$\mathrm{MS} / \mathrm{MS}$ assay was found to be $0.1 \mathrm{ng} / \mathrm{mL}$. These results indicated that the assays provided good linearity and sensitivity for their specific applications.

\section{Pharmacodynamic Evaluation}

$\mathrm{BALB} / \mathrm{c}$ mice were used to investigate the pharmacodynamic effect of TAC SLNs-ISG in this study. The grouping information was as follows: A: Normal (without any treatment, positive control); B: PBS (negative control); C: $0.1 \%$ (w/v) TAC eye drop; D: 0.1\% (w/v) TAC-SLNs; E: $0.1 \%$ (w/v) TAC-SLNs ISG. (1)Sensitization stage: BALB/c mice were intraperitoneal injected with Ovalbumin (OVA, $100 \mu \mathrm{g}$ and $35 \mu \mathrm{g} \mathrm{Al}(\mathrm{OH})_{3}$ in $200 \mu \mathrm{L}$ PBS) on immun-day 1. (2)Immune intervention stage: on immun-day 7, the eyes were challenged with different formulations three times 
a day for 5 days of the B, C, D, E group. (3) Stimulation stage:

Ova $(10 \mu \mathrm{L}, 5 \mathrm{mg} / \mathrm{mL})$ was dissolved in PBS $(\mathrm{pH}=7.0)$ after drug immune intervention treatment. The mice in groups B, C, D, E were injected with a micro sampler to induce the clinical symptoms of immune conjunctivitis. The clinical symptoms of immune conjunctivitis were observed and scored once a day for one week. Then the eyes were examined under microscope, and the scoring was performed at the same time every day and carried out once daily from day 1 to day 7. As shown in Table 1, mice were examined biomicroscopically based on 3 independent parameters. Each parameter was ascribed 0 (none) to $3+$ points (serious) and was summed to yield a maximum score of 9+. (4)After OVA challenge induced immune conjunctivitis, mice in groups $\mathrm{B}$, $\mathrm{C}, \mathrm{D}$, and $\mathrm{E}$ were treated with PBS, $0.1 \%$ TAC eye drop, $0.1 \%$ TAC-SLNs, $0.1 \%$ TAC-SLNs ISG one time a day for 5 days. Scores of various systems in different groups were calculated and graphed. After pharmacodynamic study, OVA-s IgE, IFN- $\gamma$ and IL-4 concentration in different treatment groups of mice were determined, respectively.

Meanwhile the pathological sections of corneal tissue of all groups were also observed. All animal experiments were performed in accordance with institutional guidelines, following the protocol approved by the Ethics Committees of Chongqing Medical University (19A2040). Strictly follow the National Institutes of health laboratory animal care and use guidelines.

\section{Permeability Studies}

Permeability studies were performed on the corneas isolated from rabbit whole eyes. The eyes were stored in Hanks' balanced salt solution under ice-cold condition and shipped overnight. Immediately upon their receipt, the corneas were carefully separated, and used for the permeability studies. The isolated corneas were washed in ice-cold Dulbecco's phosphate buffer saline (DPBS) solution, $\mathrm{pH}$ 7.4. The tissues were then mounted on Valia-Chien diffusion cells with the epithelial surface towards the donor chamber. The temperature of the diffusion cells was maintained at $32{ }^{\circ} \mathrm{C}$ with a circulating water bath, throughout the studies.

TAC concentration in eye drops, SLNs and SLNsISG were kept at $0.1 \% \mathrm{w} / \mathrm{v}$, and about $1 \mathrm{~mL}$ of the formulation was added to the donor chamber of the respective diffusion cells. Five milliliters of DPBS with $5 \% \mathrm{w} / \mathrm{v}$ hydroxyl propyl beta cyclodextrin (HPßCD) solution was used as the receiver medium and stirred continuously with magnetic stirrer. Samples $(500 \mu \mathrm{L})$ were withdrawn from the receiver chamber at the predetermined time points up to $2 \mathrm{~h}$ and replaced with an equal amount of DPBS-5\% HPßCD solution to maintain sink conditions. The samples were stored at $-80{ }^{\circ} \mathrm{C}$ until further analysis by HPLC. The analyses for all the samples were carried out in triplicate.

The cumulative amount of TAC was calculated as per the equation:

$$
M_{n}=V_{r} C_{r(n)}+\sum_{x=1}^{x=n} V_{s(x-1)} C_{r(x-1)}
$$

where $\mathrm{n}$ is sampling time point; $\mathrm{Vr}$ and $\mathrm{Vs}$ are the volume in the receiver chamber $(\mathrm{mL})$ and the volume of the sample collected at the nth time point $(\mathrm{mL})$, respectively; and $\operatorname{Cr}(\mathrm{n})$ is the concentration of the drug in the receiver chamber medium at $n$th time point $(\mu \mathrm{g} / \mathrm{mL})$.

The rate of TAC transported across rabbit cornea was calculated using the slope of the cumulative amount of TAC transported versus time plot. The steady state flux of TAC was determined using the following equation:

$\operatorname{Flux}(\mathrm{J})=(\mathrm{dM} / \mathrm{dt}) / \mathrm{A}$

where $\mathrm{M}$ is the cumulative amount of drug transported and $\mathrm{A}$ is the surface area of the cornea $\left(0.625 \mathrm{~cm}^{2}\right)$.

The transcorneal permeability of TAC was calculated by the following equation:

Permeability $=$ Steady state flux/Donor concentration.

Table I Scoring of Conjunctivitis Signs and Symptoms

\begin{tabular}{|l|l|l|l|l|}
\hline $\begin{array}{l}\text { Conjunctivitis } \\
\text { Symptoms (Score) }\end{array}$ & $\begin{array}{l}\text { None } \\
(\mathbf{0})\end{array}$ & Slight (1) & Medium (2) & Serious (3) \\
\hline Conjunctival congestion & $(-)$ & Pink & Red & Dark red \\
\hline Blepharoptosis & $(-)$ & $\begin{array}{l}\text { Edema of lower } \\
\text { eyelid only }\end{array}$ & $\begin{array}{l}\text { The upper and lower eyelids are edema, and } \\
\text { the eyelids are partially closed }\end{array}$ & $\begin{array}{l}\text { The eyelid is ectropion, edema is } \\
\text { obvious, and the eyelids are closed }\end{array}$ \\
\hline Secretion & $(-)$ & $\begin{array}{l}\text { Mucilaginous } \\
\text { liquid }\end{array}$ & The hair around the eyelids is moist & $\begin{array}{l}\text { The hairs on the eyelids and around } \\
\text { them are moist and sticky }\end{array}$ \\
\hline
\end{tabular}




\section{Statistical Analysis}

The results were analyzed by extreme value analysis and ANOVA. SPSS software was used for statistical analysis. The difference was significant when $\mathrm{p}<0.05$.

\section{Results and Discussion}

\section{Preparation and Characterization}

The main purpose of the study is to develop SLNs and its corresponding in situ gel to retard the clearance of TAC in the eyes and increase drug absorption. According to the solubility of the drug in the lipid phase (using GMS, and Compritol 888 ATO as the lipid phase), Tween 80 and glycerol were selected as the aqueous phase to design, prepare and optimize the SLN formulation.

TAC-SLNs ISG were prepared using homogenization followed by probe sonication method. The physicochemical properties including particle size, encapsulation efficiency (EE\%) were listed in Table 2. The average particle size of TAC-SLNs ISG was observed to be $122.3 \pm 4.3 \mathrm{~nm}$. Compared with TAC-SLNs, in situ gel did not increase particle size, and there was no significant difference between them. Some researchers think that PDI value in the range of 0.01-0.5 represents a sufficiently narrow distribution range. In the case of TAC SLNs ISG, the PDI value of 0.21 was in this range, so it was considered to be a more uniform highthroughput and high permeability formulation, as shown by in vitro release data. ${ }^{25}$

\section{Viscosity Experiments}

The residence time of the ophthalmic formulation at the precorneal surface is affected by its viscosity that is of importance for enhancing the residence time. In context to

Table 2 The Characteristics of TAC-SLNs ISG and TAC-SLNs

\begin{tabular}{|l|l|l|l|l|}
\hline \multirow{2}{*}{ Parameters } & \multirow{2}{*}{$\begin{array}{l}\text { TAC- } \\
\text { SLNs }\end{array}$} & \multicolumn{3}{|l|}{ TAC-SLNs ISG } \\
\cline { 3 - 5 } & $\mathbf{0 ~} \mathbf{~ m}$ & $\mathbf{I ~} \mathbf{~ m}$ & $\mathbf{3} \mathbf{~ m}$ \\
\hline $\begin{array}{l}\text { Particle size } \\
(\mathrm{nm})\end{array}$ & $121.5 \pm 3.8$ & $122.3 \pm 4.3$ & $125.5 \pm 5.1$ & $127.4 \pm 5.4$ \\
\hline $\begin{array}{l}\text { Encapsulation } \\
\text { efficiency (\%) }\end{array}$ & $84.6 \pm 6.2$ & $85.9 \pm 7.2$ & $84.4 \pm 6.7$ & $82.6 \pm 4.3$ \\
\hline $\begin{array}{l}\text { Polydispersity } \\
\text { index }\end{array}$ & 0.24 & 0.21 & 0.24 & 0.26 \\
\hline $\begin{array}{l}\text { Zeta potentials } \\
\text { (mV) }\end{array}$ & $-23.7 \pm 3.8$ & $-26.8 \pm 3.4$ & $-28.4 \pm 4.1$ & $-29.3 \pm 4.5$ \\
\hline
\end{tabular}

Note: $(n=3)$. ocular physiology, the range of shear rate experienced during relative movement of eyelids and globe is extremely wide ranging from 0.03 to $0.14 \mathrm{~s}^{-1}$ during inter blinking period to $4250-28,500 \mathrm{~s}^{-1}$ during a blink. Thus the viscosity of formulation should not be such that it disturbs the pseudoplastic behavior of tear film in the eye. ${ }^{26}$ Hence it is advisable to use a polymer with pseudoplastic character. ${ }^{27}$ Many literatures have confirmed that the gel prepared by poloxamer has the characteristics of pseudoplastic fluid. ${ }^{28,29}$ In order to study the effect of temperature on gelation, the viscosity of the gel was determined. The results of viscosity measurement showed that TAC-SLNs-ISG was a typical pseudoplastic system. With the increase of temperature, the viscosity increased obviously, and finally the rigid gel was formed. The gelation temperature of the prepared thermogelling gels was $32^{\circ} \mathrm{C}$ (Figure 1). At the same time, the viscosity of TACSLNs system did not increase with the change of temperature, and it always maintained at a relatively low viscosity level.

\section{In vitro Release}

The in vitro drug release curve of TAC SLNs-ISG, TAC SLNs and free TAC were shown in Figure 2. At the end of the experiment, nearly $80 \%$ of the drug was released in TAC SLNs group, while only $56 \%$ in TAC SLNs-ISG group did so. The release curve of TAC SLNs-ISG was a two-phase model. TAC SLNs-ISG released quickly at the early stage (about 30\% TAC was released within 1 hour), and then released slowly. This phenomenon is mainly caused by the release of drugs dispersed in the gel. In the late stage, the sustained release was due to the fact that with the dissolution and diffusion mechanisms on the lipid matrices and polymer material, the solubilized or dispersed drug can only be released slowly. As was shown in Table 3, the Higuchi equation: $Q=9.287 \mathrm{t} 1$ / 2-2.263 ( $\mathrm{r}=0.994)$ was the best fit well with the release kinetic model of TAC SLNs-ISG. Therefore, it was speculated that the sustained-release characteristics of TAC SLNs-ISG may enhance the ocular absorption of TAC.

\section{Stability Studies}

There were negligible alterations in the initial values of viscosity of the formulations over a storage of 3 months. The samples were also analyzed for drug content by HPLC analysis (data not shown). Again the drug degraded to a negligible extent, and the percentage of drug degradation is $<5 \%$. Other stability parameters are shown in Table 2 . 




Figure I (A) Photographs of in situ gels formed before $\left(4^{\circ} \mathrm{C}\right)$ and after $\left(37^{\circ} \mathrm{C}\right)$ gelation. (B) Mean viscosity-temperature trends profiles of TAC SLNs and TAC SLNs-ISG. $(n=3)$.



Figure 2 The in vitro drug release profiles of TAC eye drops, TAC SLNs and TAC SLNs-ISG. Number represents the percentage of release. $(n=6)$.

\section{In vivo Kinetics}

The concentration in tear-time plots, in rabbits after ophthalmic administration of test formulations are shown in Figure 3 and the AUC parameters are

Table 3 Release Kinetic of TAC SLNs-ISG

\begin{tabular}{|l|l|l|}
\hline \multirow{2}{*}{} & \multicolumn{2}{|l|}{ TAC SLNs-ISG } \\
\cline { 2 - 3 } & Equation & $\begin{array}{l}\text { Correlation } \\
\text { Coefficient (R) }\end{array}$ \\
\hline Zero-order & $\mathrm{Q}=4.3 \mathrm{I} 2 \mathrm{t}+0.2 \mathrm{I7}$ & $0.93 \mathrm{I}$ \\
\hline First-order & $\operatorname{Ln}(\mathrm{I}-\mathrm{Q})=-3.287 \mathrm{t}+0.673$ & $0.97 \mathrm{I}$ \\
\hline Weibull & $\begin{array}{l}\ln \ln (\mathrm{I} /(\mathrm{I}-\mathrm{Q}))=4.938 \mathrm{Int} \\
+\mathrm{I} .332\end{array}$ & 0.954 \\
\hline Higuchi & $\mathrm{Q}=9.287 \mathrm{t} \mathrm{I} / 2-2.263$ & 0.994 \\
\hline
\end{tabular}

Note: $(n=6)$. 


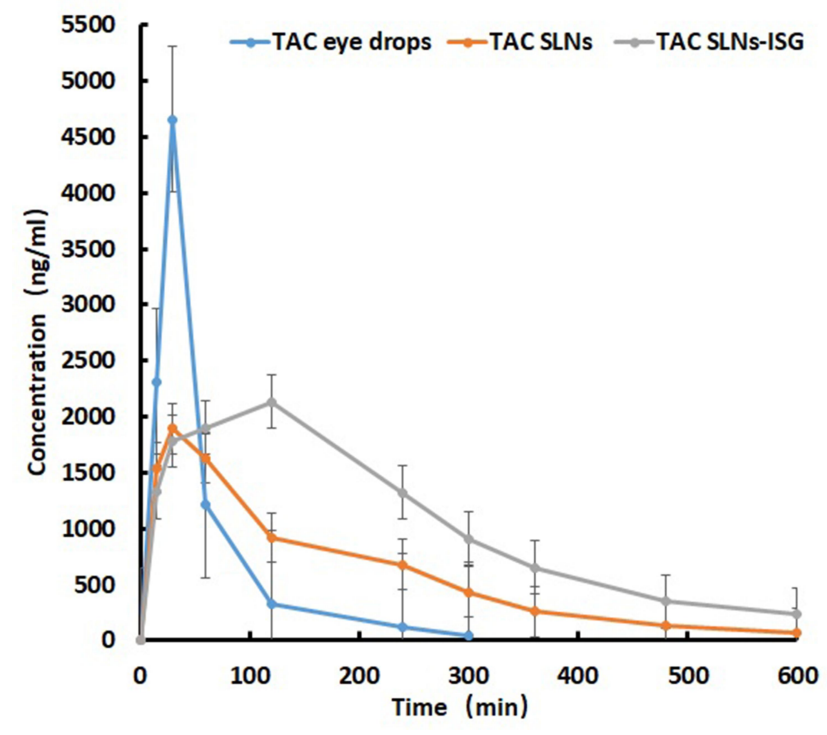

Figure 3 Concentration-time curve of TAC in different formulations (TAC eye drops, TAC SLNs and TAC SLNs-ISG). $(n=6)$.

tabulated in Table 4. The Tmax was $30 \mathrm{~min}$ and the Cmax was $4657.7 \mathrm{ng} / \mathrm{mL}$ after ophthalmic administration of TAC eye drops. However, the time to achieve maximum concentration of TAC was delayed in the form of ISG. For TAC-SLNs, highest drug concentration of $1892.6 \mathrm{ng} / \mathrm{mL}$ was observed at the 30th min, whereas TAC-SLNs-ISG showed maximum concentration (2132.3 ng/mL) at the second hour. The Cmax of TACSLNs and TAC-SLNs-ISG was significantly $(p<0.05)$ lower than that obtained within the TAC eye drops. The AUC0-t of TAC-SLNs-ISG was $590,355.9 \mathrm{ng} \cdot \mathrm{min} / \mathrm{mL}$, 2.65 folds higher than AUC0-t of $222,382.5 \mathrm{ng} \cdot \mathrm{min} / \mathrm{mL}$ for TAC eye drops, clearly defining performance superiority of in situ gels over drops. SLNs are believed to be actively engulfed by the corneal and conjunctival cells. This is considered to be the main advantage of colloidal dispersion. In addition to passive diffusion out of the SLNs, the lipases in the tear film and in the epithelial cells are also responsible for the controlled release of TAC. Release occurs both in the tear as well as in the

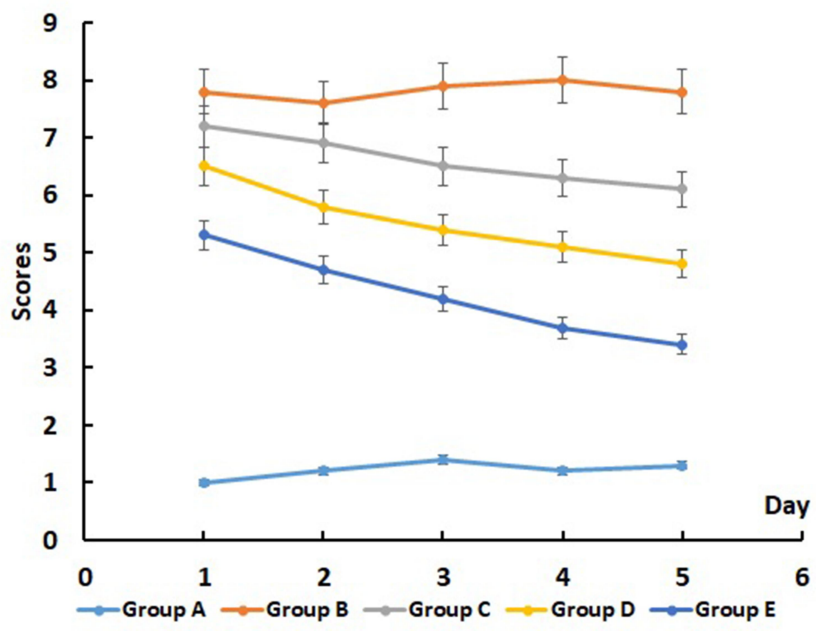

Figure 4 The pharmacodynamic scores in different groups. Group A: Normal (untreated, positive control); Group B: PBS (negative control); Group C: $0.1 \%$ TAC eye drop; Group D: 0.1\% TAC-SLNs; Group E: $0.1 \%$ TAC-SLNs ISG. $(n=6)$.

corneal matrix. Therefore, in vivo kinetics studies can show the slow release characteristics of drugs from gels.

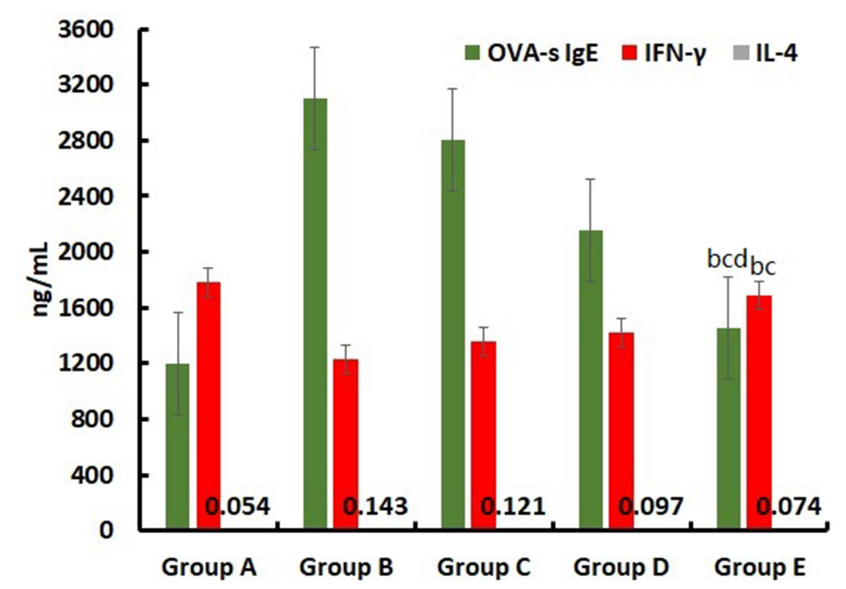

Figure 5 OVA-s IgE, IFN- $\gamma$ and IL-4 concentration of different treatment groups in mice after pharmacodynamic study. Group A: Normal (untreated, positive control); Group B: PBS (negative control); Group C: 0.1\% TAC eye drop; Group D: $0.1 \%$ TAC-SLNs; Group E: $0.1 \%$ TAC-SLNs ISG. $(n=6) .{ }^{b}<<0.05$, Group E vs Group B; ${ }^{c} \mathrm{p}<0.05$, Group E vs Group C; ${ }^{d} \mathrm{p}<0.05$, Group E vs Group B.

Table 4 Ocular Tear Pharmacokinetic Parameters of TAC in Tear versus Time Profiles in 600 Min for Various Formulations

\begin{tabular}{|l|l|l|l|l|l|l|}
\hline Formulation & $\begin{array}{l}\text { Cmax } \\
(\mathbf{n g} / \mathbf{m L})\end{array}$ & $\begin{array}{l}\text { Tmax } \\
(\mathbf{h})\end{array}$ & $\begin{array}{l}\text { MRT } \\
\mathbf{( h )}\end{array}$ & $\begin{array}{l}\text { TI/2 } \\
\text { (h) }\end{array}$ & $\begin{array}{l}\text { AUC0-t } \\
(\mathbf{n g} \mathbf{m i n} / \mathbf{m L})\end{array}$ & $\begin{array}{l}\text { AUC 0-t } \\
\text { Ratio }\end{array}$ \\
\hline TAC eye drops & $4657.7 \pm 412.2$ & $30.2 \pm 4.3$ & $1.28 \pm 0.45$ & $1.84 \pm 0.76$ & $222,382.5 \pm 20,192.5$ & - \\
TAC-SLNs & $1892.6 \pm 206.4^{*}$ & $33.6 \pm 8.9$ & $2.07 \pm 0.92$ & $3.72 \pm 0.88^{*}$ & $339,555.4 \pm 31,927.2^{*}$ & 1.53 \\
TAC-SLNs-ISG & $2132.3 \pm 241.6^{*}$ & $120.6 \pm 11.6^{*}$ & $2.82 \pm 1.21^{*}$ & $3.92 \pm 0.94^{*}$ & $590,355.9 \pm 57,281.7^{*}$ & 2.61 \\
\hline
\end{tabular}

Notes: Each value represents the mean \pm SD of three determinations. ${ }^{*} p<0.05$ (compared to TAC eye drops). ( $\left.n=6\right)$. 


\section{Pharmacodynamic Evaluation}

The establishment of the animal model in this study was completely successful, and there were significant differences between the positive control group and the negative control group (Figure 4).

In the untreated group (Group A), there were almost no symptoms, so the score remained at a relatively low level during the observation period. The symptoms of the positive control group (Group B) were more obvious, and the score was always at a high level. In this experiment, the unified administration time of each group was morning, and the unified time of scoring statistics was afternoon, so on the first day after treatment, there was a significant difference between the three groups. The scores of the three experimental groups (Group C, D, E) showed different degrees of decline from the first day. The effect of group $\mathrm{E}$ was the most obvious, and the improvement of symptoms was the most obvious on the fifth day of the experiment. The reason for the relatively short retention time of the eye drops and TAC-SLNs is that they are not completely observed by the naked eye. Through the detection of three biochemical indexes (OVA-s IgE, IFN- $\gamma$ and IL-4), Group E has significant curative effect on conjunctivitis compared with other control groups $(\mathrm{p}<0.05$, Figure 5). The mechanism of TAC's action is to inhibit the activation and degranulation of conjunctival mast cells, inhibit the release of inflammatory mediators by mast cells, and down regulate IL-4 in serum, thus inhibiting the antibody response of $\mathrm{B}$ cells from $\operatorname{IgM}$ to $\operatorname{IgE}$ and reducing
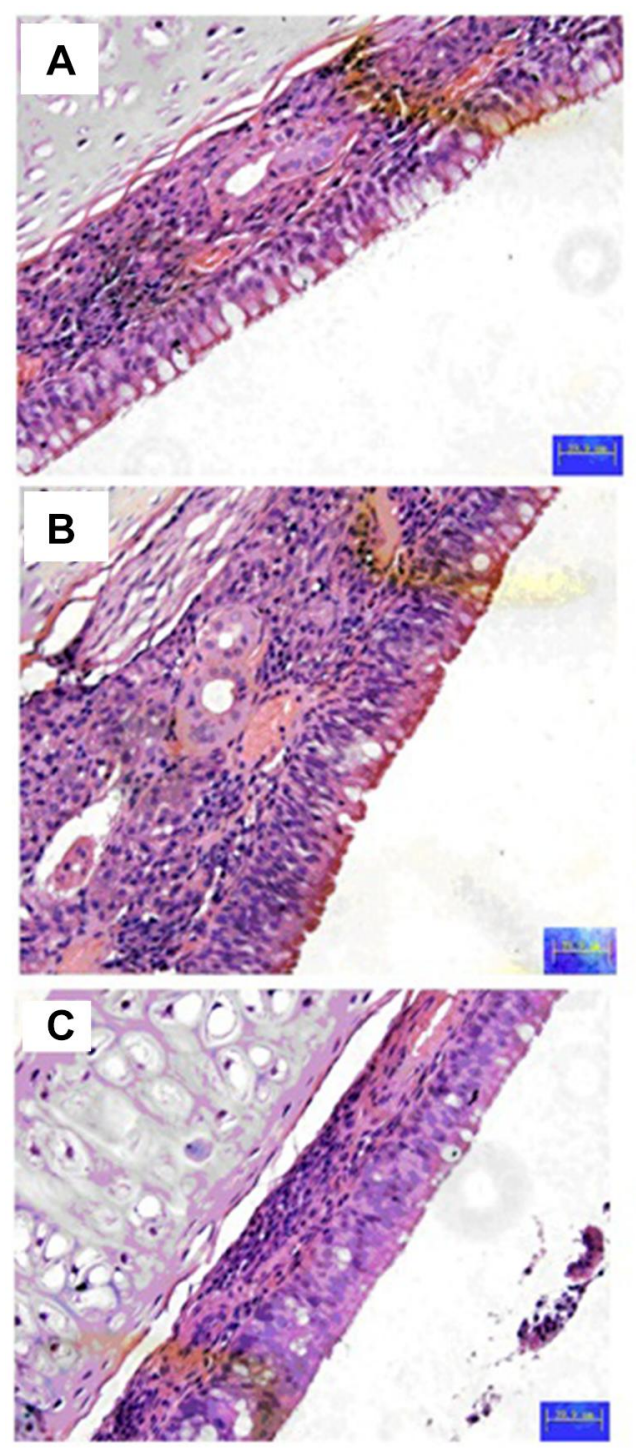


Figure 6 Histopathological studies of corneal tissue of different groups. (A) normal; (B) TAC SLNs (C) TAC SLNs-ISG. Left: treatment eye; Right: un-treatment eye. 
Table 5 The Result of Permeability and Flux of Different TAC Formulation

\begin{tabular}{|l|l|l|}
\hline Formulation & $\begin{array}{l}\text { Permeability } \\
\left(* 10^{-6} \mathbf{c m} / \mathbf{s e c}\right)\end{array}$ & $\begin{array}{l}\text { Flux } \\
\left(\mu \mathrm{g} / \mathbf{m i n} / \mathbf{c m}^{2}\right)\end{array}$ \\
\hline TAC eye drops & $0.91 \pm 0.08$ & $0.062 \pm 0.007$ \\
TAC-SLNs & $9.15 \pm 1.34^{*}$ & $0.12 \pm 0.04^{*}$ \\
TAC-SLNs-ISG & $8.26 \pm 0.73^{*}$ & $0.065 \pm 0.004$ \\
\hline
\end{tabular}

Notes: Each value represents the mean \pm SD of three determinations. ${ }^{*} \mathrm{p}<0.05$ (compared to TAC eye drops). $(n=6)$.

the synthesis of IgE. Through up regulating IFN $-\gamma$ in serum, the proliferation of Th2 cells and the function of IL-4 are inhibited, and the transformation of Th1 to Th2 is inhibited, so that Th1 and Th2 are in a dynamic balance state. Through this mechanism, type I allergy can be controlled and immune conjunctivitis can be treated. Through the optimization of dosage forms (SLNs or in situ gel), the therapeutic effect is further expanded. Corneal histopathology of showed that TACSLNs-ISG had good safety (Figure 6).

Permeability test

The permeability coefficient and flux for TAC in eye drops, SLNs and SLNs-ISG is calculated in Table 5. The transcorneal permeability and flux of TAC from SLNs was significantly higher compared to that of the eye drops. This indicates that the lipid nanoparticles enhance the permeation of the drug through intact corneal tissues. The slightly lower flux and permeability of TAC from the SLNs-ISG compared with SLNs indicates the controlled release of the drug from the higher viscosity formulation.

\section{Conclusion}

The aim of this study is to develop a novel in situ gel of tacrolimus-loaded SLNs for ocular drug delivery. In this study, TAC-SLNs ISG were prepared using homogenization followed by probe sonication method. The average particle size of TAC-SLNs ISG was observed to be $122.3 \pm 4.3 \mathrm{~nm}$. Compared with TAC-SLNs, in situ gel did not increase particle size, and there was no significant difference between them. The results of viscosity measurement showed that TAC SLNs-ISG were typical of pseudo plastic systems and showed a marked increase in viscosity as temperature increased and ultimately formed a rigid gel $\left(32^{\circ} \mathrm{C}\right)$. In vitro and in vivo studies illustrated the sustained release model of the drug from TAC-SLNs ISG. Animal model showed that TAC-SLNs ISG had good pharmacodynamics when compared with eye drops and SLNs. Our results demonstrated that TAC SLNs-ISG has potential as an ideal ocular drug delivery system.

\section{Acknowledgments}

We wish to express our thanks to Dr. Wei ZHU (Department of Pharmaceutical, School of Pharmacy, Fudan University, Shanghai, China) for his help in the study design.

\section{Disclosure}

The authors report no conflicts of interest for this work.

\section{References}

1. Maurice DM. Kinetics of topical applied drugs. In: Saettone MS, Bucci P, Speiser P, editors. Ophthalmic Drug Delivery: Biopharmaceutical, Technological and Clinical Aspects. Padova: Liviana Press; 1987:19-26.

2. Pleyer U, Lutz S, Jusko W, et al. Ocular absorption of topically applied FK506 from liposomal and oil formulations in rabbit eye. Invest Ophthalmol Vis Sci. 1993;34(9):2737-2742.

3. Bochot A, Fattal E, Grossiord JL, Puisieux F, Couvereur P. Characterization of a new ocular delivery system based on a dispersion of liposomes in a thermosensitive gel. Int $J$ Pharm. 1998;162:119-127. doi:10.1016/S0378-5173(97)00419-5

4. de Campos AM, Diebold Y, Carvaiho EL, Sanchez A, Alonso MJ. Chitosan nanoparticles as new ocular drug delivery system: in vitro stability, in vivo fate, and cellular toxicity. Pharm Res. 2004;21 (5):803-810. doi:10.1023/B:PHAM.0000026432.75781.cb

5. Nayak K, Misra M, Nayak K, et al. A review on recent drug delivery systems for posterior segment of eye. Biomed Pharmacother. 2018;107:1564-1582. doi:10.1016/j.biopha.2018.08.138

6. Bachu RD, Chowdhury P, Al-Saedi ZHF, et al. Ocular drug delivery barriers-role of nanocarriers in the treatment of anterior segment ocular diseases. Pharmaceutics. 2018;10(1):28. doi:10.3390/ pharmaceutics 10010028

7. De Campos AM, Sánchez A, Gref R, Calvo P, Alonso MJ. The effect of PEG versus a chitosan coating on the interaction of drug colloidal carriers with the ocular mucosa. Eur J Pharm Sci. 2003;20(1):73-81. doi:10.1016/S0928-0987(03)00178-7

8. Lakhani P, Patil A, Majumdar S, et al. Recent advances in topical nano drug-delivery systems for the anterior ocular segment. Ther Deliv. 2018;9(2):137-153. doi:10.4155/tde-2017-0088

9. Ferraboschi P, Colombo D, De Mieri M, et al. Evaluation, synthesis and characterization of tacrolimus impurities. $J$ Antibiot (Tokyo). 2012;65(7):349-354. doi:10.1038/ja.2012.28

10. Honbo T, Kobayashi M, Hane K, Hata T, Ueda Y. The oral dosage form of FK-506. Transplant Proc. 1987;19(5 Suppl 6):17-22.

11. Arima H, Yunomae K, Miyake K, Irie T, Hirayama F, Uekama K. Comparative studies of the enhancing effects of cyclodextrins on the solubility and oral bioavailability of tacrolimus in rats. J Pharm Sci. 2001;90(6):690-701. doi:10.1002/jps.1025

12. Gao S, Sun J, Fu D, Zhao H, Lan M, Gao F. Preparation, characterization and pharmacokinetic studies of tacrolimus-dimethyl- $\beta$ cyclodextrin inclusion complex-loaded albumin nanoparticles. Int J Pharm. 2012;427(2):410-416. doi:10.1016/j.jjpharm.2012.01. 054

13. Kwon M, Yeom D, Kim NA, et al. Bioequivalence of tacrolimus formulations with different dynamic solubility and in-vitro dissolution profiles. Arch Pharm Res. 2015;38(1):73-80. doi:10.1007/ s12272-014-0343-3 
14. Skytte DM, Jaroszewski JW, Johansen KT, et al. Some transformations of tacrolimus, an immunosuppressive drug Eur. J Pharm Sci. 2013;48(3):514-522.

15. Loftsson T, Muellertz A, Siepmann J. For the special IJP issue "Poorly soluble drugs". Int J Pharm. 2013;453(1):1-2. doi:10.1016/ j.ijpharm.2013.05.056

16. Xiao P, Dudal Y, Corvini P, Spahr P, Shahgaldian P. Synthesis and characterization of fluoroquinolone-imprinted polymeric nanoparticles. React Funct Polym. 2012;72:287-293. doi:10.1016/j.reactfunctpolym. 2012.02.006

17. Müller RH, Mäder K, Gohla S. Solid lipid nanoparticles (SLN) for controlled drug delivery-A review of the state of the art. Eur $J$ Pharm Biopharm. 2000;50(1):161-177. doi:10.1016/S0939-6411 (00)00087-4

18. Mehnert W, Mäder K. Solid lipid nanoparticles. production, characterization and applications. Adv Drug Deliv Rev. 2001;47(2-3):165-196. doi:10.1016/S0169-409X(01)00105-3

19. Khames A, Khaleel MA, El-Badawy MF, El-Nezhawy AOH. Natamycin solid lipid nanoparticles - sustained ocular delivery system of higher corneal penetration against deep fungal keratitis: preparation and optimization. Int J Nanomedicine. 2019;14:2515-2531. doi:10.2147/IJN.S190502

20. Tatke A, Dudhipala N, Janga KY, et al. In situ gel of triamcinolone acetonide-loaded solid lipid nanoparticles for improved topical ocular delivery: tear kinetics and ocular disposition studies. Nanomaterials (Basel). 2018;9(1):33. doi:10.3390/nano9010033

21. Balguri SP, Adelli GR, Majumdar S. Topical ophthalmic lipid nanoparticle formulations (SLN, NLC) of indomethacin for delivery to the posterior segment ocular tissues. Eur J Pharm Biopharm. 2016;109:224-235. doi:10.1016/j.ejpb.2016.10.015

22. Yadav M, Schiavone N, Guzman-Aranguez A, et al. Atorvastatinloaded solid lipid nanoparticles as eye drops: proposed treatment option for age-related macular degeneration (AMD). Drug Deliv Transl Res. 2020;10(4):919-944. doi:10.1007/s13346-02000733-4
23. Narendar D, Kishan V. Candesartan cilexetil loaded solid lipid nanoparticles for oral delivery: characterization, pharmacokinetic and pharmacodynamic evaluation. Drug Deliv. 2016;23(2):395-404. doi:10.3109/10717544.2014.914986

24. Yu L, Zhang Z, Zhang H, Ding J. Biodegradability and biocompatibility of thermoreversible hydrogels formed from mixing a sol and a precipitate of block copolymers in water. Biomacromolecules. 2010;11(8):2169-2178. doi:10.1021/bm100549q

25. Rakesh K, Sinha VR. Solid lipid nanoparticle: an efficient carrier for improved ocular permeation of voriconazole. Drug Dev Ind Pharm. 2016;42(12):1956-1967. doi:10.1080/03639045.2016.1185437

26. Giannavola $\mathrm{C}$, Bucolo $\mathrm{C}$, Maltese $\mathrm{A}$, et al. Influence of preparation conditions on acyclovir- loaded poly-d, 1-lactic acid nanospheres and effect of PEG coating on ocular drug bioavailability. Pharm Res. 2003;20(4):584-590. doi:10.1023/A:1023290514575

27. Srividya B, Cardoza RM, Amin PD. Sustained ophthalmic delivery of ofloxacin from a $\mathrm{pH}$ triggered in-situ gelling system. J Control Release. 2001;73(2-3):205-211. doi:10.1016/S0168-3659(01)00279-6

28. Moreira TS, de Sousa VP, Pierre MB. Influence of oleic acid on the rheology and in vitro release of lumiracoxib from poloxamer gels. J Pharm Pharm Sci. 2010;13(2):286-302. doi:10.18433/J34880

29. Perez AP, Mundiña-Weilenmann C, Romero EL, Morilla MJ. Increased brain radioactivity by intranasal P-labeled siRNA dendriplexes within in situ-forming mucoadhesive gels. Int J Nanomedicine. 2012;7:13 73-1385. doi:10.2147/IJN.S28261
Drug Design, Development and Therapy

\section{Publish your work in this journal}

Drug Design, Development and Therapy is an international, peerreviewed open-access journal that spans the spectrum of drug design and development through to clinical applications. Clinical outcomes, patient safety, and programs for the development and effective, safe, and sustained use of medicines are a feature of the journal, which has also

\section{Dovepress}

been accepted for indexing on PubMed Central. The manuscript management system is completely online and includes a very quick and fair peer-review system, which is all easy to use. Visit http://www. dovepress.com/testimonials.php to read real quotes from published authors. 